\title{
Hypocritical Behavior and Organization Size: A Game-theory Approach
}

\author{
Zagross Hadadian \\ Corresponding Author, Faculty of Economics and Business, University of Applied Science and Technology \\ Zar center, Iran; Email:Zagrossfuture@gmail.com
}

Hamidreza Navidi

Associate Professor of Applied Mathematics, Shahed University,Iran.Email:Navidi@shahed.ac.ir

Kourosh Shafei Digehsara

PhD candidate of management, Azerbaijan National Academy of Science, Azerbaijan

Email:kourosh.shafei@gmail.com

Fatemeh Zaer Sabet

PhD candidate of human resource management, Islamic Azad University of Qazvin, Qazvin, Iran Email: Fatemeh_zear@yahoo.com

\section{Doi:10.5901/mjss.2016.v7n1p159}

Abstract

This article seeks to address hypocritical behavior in interpersonal communication in organizations and it's relationship with organization size. In the first step our game theory model studies the hypocritical behavior between two persons. In the next step, with some adjustments, the model studies hypocritical behavior in the organization. This research provides a unique mathematical model on the use of hypocritical behavior and interestingly suggests that, the larger is the organizational size (number of members), the greater is the risk that all members of the organization turn to adopt a hypocritical behavior.

Keywords: Hypocrisy; Trust; Game Theory

\section{Introduction}

A rapidly growing body of literature suggests that trust plays an important role in employee relationships, and consequently, organizational success (Simoms, 2002; McAllister, 1995 ;Sankowska, 2013; Braun et al., 2013).Trust brings about cooperation (Tyler, 2003) and enhances the performance of working groups (Cazier et al., 2007). Trust is a multifaceted concept with different proposed definitions (Velez, 2000); however, it generally expresses the confidence one has in another to act in a moral and fair manner (Nyhan, 2000). Trust and its dimensions in an organization have been studied from different perspectives, leading to a concept defined as "organizational trust"(Kramer and Lewicki, 2010; Li et al., 2012). It refers to the individual positive perceptions people have about the content and behavior of members of the organization (Shockley-Zalabak et al., 2000). In this section, it is not intended to introduce a complete list of definitions for trust, as it has been remarkably done by Bigley and Pearce (1998) and Kramer (1999). Instead, the intent is to establish the following point:

Although researchers have proposed various definitions for trust, there exists a substantial agreement: perception of alignment between the words and the deeds is of importance in creating trust (Simoms, 2002).

Current definition introduces the behavioral integrity $(\mathrm{BI})$ as the perceived pattern of alignment between an actor's words and deeds. It should be noted that while BI looks at the past, trust considers the future. According to these definitions, one would expect that BI is an antecedent of trust (Mayer et al., 1995). Since hypocrisy may be considered as an antonym of $\mathrm{BI}$ (Brunsson, 1989), hypocrisy is the cause of distrust in organizations, which has been confirmed by other studies (Golembiewski and McConkie, 1975).

A brief review of organizational trust and the role of hypocritical behavior in disturbing the organizational trust atmosphere reveal the need for further research in this area. The present study attempts to investigate the relationship 
between the organizational size in terms of the number of employees and promotion of such behaviors in organizations through modeling hypocritical behaviors in interpersonal relationships.

\section{Literature Review}

Hypocritical behavior in interpersonal communication in organization is a behavior in which some members of the organization in at least two identical communicational situations behave differently or contradictorily; however, just one of those behaviors may be compatible with the actual attitude of the owner of the behavior or sometimes neither of these behaviors is compatible with the actual attitude. Hypocritical behavior has many outcomes, for instance it can darken the trust atmosphere in interpersonal communication (Golembiewski and McConkie, 1975), decrease the performance of a group (Dirks and Ferrin, 2002) and consequently affect the long term stability of the organization and the tranquility of members of the organization (Cook and Wall, 1980).

According to the conceptual definition, hypocrisy is a kind of untruth that a person pretends to be sacred and justified (Gilby, 1979). Hypocrisy is also defined as not practicing what you preach (Stone and Fernandez, 2008), saying one thing and doing another (Barden et al., 2005), or publicly showing a tendency to moral norms, but personally violating them in private (Lammers et al., 2010). To put it another way, a hypocrite, in contrast to the truth, tries to show himself or herself a justified and good person (Price, 1986). From the definitions, it is clear that a growing body of literature has evaluated hypocrisy as a kind of deceptive behavior. Deceptive communications are very complicated and mostly leave no trace behind (McCornack, 1997; Buller and Burgoon, 1996). As a result we can say that hypocrisy is a covered behavior and the only symptom of such phenomenon is that a person behaves hypocritically. So hypocritical behavior is a behavior in which a member of an organization without changing his or her attitude uncovers a heterogeneous behavior for a unique attitudinal issue.

A review of literature on this topic shows the hypocrisy phenomenon from different perspectives, amongst which the most prominent are these two main views:

The first view is the social psychology view. Followers of this view believe that hypocrisy is a kind of cognitive heterogeneity in which there is an incompatibility between the current preaches of a person among people and some of his or her behavior in the past (Stone et al., 1994; Aronson, 1999; Aronson et al., 1991; Dickerson et al., 1992; Fried and Aronson, 1995). Remembering the heterogonous behavior in the past and his current preaches, a hypocrite may get hurt or face internal conflicts and may try to adjust his future behavior to his current preaches (Aronson, 1999; Dickerson et al., 1992; Fried and Aronson, 1995 ; Stone et al., 1994). As the above discussion asserts, social psychologists have concentrated on the cognitive heterogeneity derived from hypocrisy and the way the hypocrite copes with it.

The second view is the organizational behavior view. In their paper, Argyris and Schon(1974) concentrated on inter-organizational heterogeneity. They uncovered that there is a meaningful discrepancy between what is said and what is performed in organizations. They talked about the values and beliefs that are preached by managers and members of organization while these values and beliefs have no consistency with their actions. They called this perceived incompatibility between words and deeds as perceived organizational hypocrisy. This paper deals with organizational hypocrisy view.

Several researches have been carried out to study this incompatibility from different angles. For instance, Perez and Robson(1999) uncovered three main reasons for such incompatibility:

- A word that establishes an unofficial agreement.

- A decision which leads to an official policy.

- An action done by members, that is different from what they officially accepted or unofficially acknowledged.

Extensive researches also studied the result of such types of incompatibility in the organizations. For example, Jansen and Von Glinow (1985), Brunsson (1993), and Philippe and Koehler (2004) claim that comprehension of these incompatibilities may do reduce the performance and job satisfaction or may increase the tension in working places, and the tendency to leave. Many of these studies present the discrepancy between the promises and actions of high-ranking managers as a source of hypocrisy. But, why do high-ranking managers behave hypocritically? In his study, Gawthrop (1997) suggests that this behavior is because of the confusion made through simultaneity of democracy and bureaucracy. Democracy in organizations is in line with the wants of the high-ranking managers, but managers should work in the framework of the organizational bureaucracy. This dichotomy causes discrepancy.

How can a person in an organization comprehend this hypocrisy? Phillips and his colleague claim that the understanding of employees from acts of managers, culture in the organization and incentive systems are three main factors that help employees recognize hypocrisy (Philippe and Koehler, 2004). In their researches, Batson et al., (1997), Batson et al., (2002) and Batson et al., (1999) show the main reason for hypocritical behavior. They conducted their 
research with respect to moral hypocrisy. They wanted to know whether the moral action by a hypocrite is the result of the desire to be moral or the desire to appear moral. The result showed that hypocrites are concentrating on trying to appear moral, and if possible, escape from the cost of actually behaving morally (Batson et al., 1997; Batson et al., 2002 ;Batson et al., 1999). In the same context, Griffin and Ross (1991) commented that behaving immorally carries costs. The awareness of the issue that one is acting immorally ruins one's self-concept. In other words in the context of committing a hypocritical behavior, people are using a kind of cost and profit analysis in their minds. In essence, while hypocritical behavior may have some sort of job satisfaction for the hypocrites, it may carry a cost for them. Members of the organization may no longer trust the hypocrite or may behave hypocritically in response. Moreover, perceived hypocritical behavior may wipe out the positive effects of prior good deeds (Perez and Robson, 1999).

\section{Model Instruction}

The game theory was used to model this behavior in the organization. The behavior of the two members of the organization was first modeled, and all members of the organization were then considered.

\subsection{Game theory}

There are a number of definitions for game theory. For instance, Myerson (1997) defines it as a mathematical modeling of interactions among decision makers. Gibbons(1992) describes game theory as an examination of multi-person decision problems and Osborne and Rubinstein (1994), in his investigation into game theory, underlines that game theory is a batch of analytical tools used to understand a phenomena caused by decision makers interaction. On the basis of these definitions, we decide to use game theory in our paper.

From what discussed above it is clear that game theory deals with situations that involve more than one participant who are formally called players. A player may be a gambler, an investor in a stock exchange, a country in a political issue or a person in an interpersonal relationship. If there are $\mathrm{n}$ actors in a game, the actor set is shown as $N=\{1,2, \cdots, n\}$. Each actor has a strategy in its game. Strategy refers to all the measures possible for an actor. The strategy set of the Actor $\mathrm{i}$ is $\mathrm{S}_{\mathrm{i}}$. If the Actor $\mathrm{i}$ has $\mathrm{k}$ strategies, its strategy set will be.

$$
S_{i}=\left\{s_{1}, s_{2}, \ldots, s_{k}\right\} \quad i \in N
$$

When actors select their strategies, for each combination of the actors' strategies, a pay-off is obtained for each actor. The actor's pay-off in the game, which is a key element of the game, is a function of the strategies adopted by that actor and the rival actors. The actor's pay-off can be defined as follows:

Where, $\mathrm{S}$ is the Cartesian product of the actors' strategy set:

$$
S=S_{1} \times S_{2} \times \cdots \times S_{n}=\left\{\left(s_{1}, s_{1}, \cdots, s_{1}\right), \cdots,\left(s_{k}, s_{k}, \cdots, s_{k}\right)\right\}
$$

The above product gives an ordered n-tuple set, each of which is a combination of strategies selected by the actors. For example, the combination $\left(\mathrm{s}_{1}, \mathrm{~S}_{1}, \mathrm{~S}_{1}, \ldots, \mathrm{S}_{1}\right)$ indicates that the Actor 1 has selected the strategy $\mathrm{s}_{1}$, the Actor 2 has selected the strategy $s_{1}$, and the Actor $n$ has selected the strategy $s_{1}$. Therefore, when each actor selects one strategy from its own set of strategies, e.g. $s_{i} \in S_{i}$, his selected $\mathrm{si}$ along with the strategies adopted by other actors create his and his competitors' pay-offs. The pay-off of the Actor $i$ is a real number. For example, if in a game, the combination $\left(\mathrm{s}_{1}, \mathrm{~s}_{1}, \mathrm{~s}_{1}, \ldots, \mathrm{s}_{1}\right)$ is selected by the actors, the pay-off of the Actor 1 will be:

$$
u_{1}\left(s_{1}, \mathrm{~s}_{1}, \cdots, \mathrm{s}_{1}\right)=a_{1} \in R
$$
games.

The best response method was used to play the game and obtain the Nash equilibrium of the mixed strategy

The strategy combination of $s^{*}=\left(s_{1}, s_{2}, \cdots, s_{N}\right) \in S$ is called "Nash equilibrium", if for each Actor i, we have:

$u_{i}\left(s_{i}^{*}, s_{-i}^{*}\right) \geq u_{i}\left(s_{i}, s_{-i}^{*}\right) \quad \forall s_{i} \in S_{i}, \forall i \in N$

In other words, with respect to the true belief of the Actor i about the competitors' selection, i.e. $s_{-i}^{*}$, the Actor i has to select the $s_{i} \in S_{i}$ to maximize the function ${ }^{u_{i}}\left(s_{i}, s_{-i}^{*}\right)$. The function (i.e. $\left.{ }^{s_{i}} \in S_{i}\right)$ that maximizes the latter function is shown by $s_{i}^{*}$. Therefore, $s_{i}^{*}$ is the solution to the below optimization problem:

$$
\operatorname{Maxu}_{i}\left(s_{i}, s_{-i}^{*}\right) \quad \forall i \in N
$$




\subsection{Game Theory and Hypocritical Behavior in Interpersonal Communication}

The following is considered for mathematical modeling:

\begin{tabular}{cl}
\hline$N$ & The number of members of the organization \\
$V$ & The profit gained from non-hypocritical atmosphere \\
$C$ & The cost of not having hypocritical behavior \\
$H$ & Having a hypocritical behavior \\
$N H$ & Not having a hypocritical behavior \\
$p$ & Probability that a member of the organization behaves non hypocritically \\
$E_{i}(x, y)$ & Expected payoff of a mixed strategy \\
$U_{i}(k, j)$ & Utility of the player $i$ when player $i$ plays $k$ and the other player plays ${ }^{j}$ \\
$\mathrm{~N}(\mathrm{G})$ & Nash equilibrium point or set \\
\hline
\end{tabular}

In order to define the problem precisely, a set of assumptions are required:

- $V>C>0$

The model has assumed that even if one member of the organization has a non-hypocritical behavior, each member of the organization will gain $V$ unit of utility through the existence of non-hypocritical behavior in the organization. Also, the non-hypocrite member will pay as much as $\mathrm{C}<\mathrm{V}$ for his non-hypocritical behavior. The reason for the cost is that a behavior that does not conform to the group's behavior is likely to have consequences such as rejection and loss of opportunities. This cost would be less than the utility gained through the non-hypocritical behavior; as otherwise, the member's behavior would spontaneously be transformed to a hypocritical behavior.

In this model, no utility has been considered for one's hypocritical behavior, and it has been intended to address a case, in which people do not seek special utility though hypocritical behavior (It has been assumed that the only thing that the hypocrite member gain from hypocritical behaviors is avoiding the cost of being non-hypocrite and not paying the $\mathrm{C}$ unit price). With this assumption, it has been intended to direct the environment towards non-hypocritical behaviors.

It has also been assumed that the hypocritical behaviors do not impose costs on others. This assumption has also been made to place people under the minimum pressure to adopt hypocritical behavior. For example, if the cost from others' hypocritical behavior on the Actor 1 increases, when calculating the utility of his non-hypocritical behavior, the Actor 1 would be forced to subtract an amount, due to the hypocritical behavior of the others, and tend less to adopt dishonest behavior. Therefore, it can be said that all assumption are made to keep the people's willingness to nonhypocritical behavior high.

In 1950, Nash Jr (1950) introduced Nash equilibrium in which each of $N$ players believe that his strategy is the best response to strategies of other player. In their paper, Holt and Roth (2004) proposed that:

"a Nash equilibrium is a set of strategies, one for each of $n$ players of a game, that has the property that each player's choice is his best response to the choices of $n-1$ other players. It would survive an announcement test: If all players announce their strategy simultaneously, nobody would want to reconsider." A theorem asserts that every game with a finite number of players and action profiles has at least one nash equilibrium (Nash Jr, 1950), so if we assume that player 1 and player 2 are two members of an organization, and if there is a mixed equilibrium in which player 1 randomizes, there must be a case in which player 1 is indifferent between not having a hypocritical behavior $(\mathrm{NH})$ and having a hypocritical behaior $(H)$.

If we set a classical game for two actors, we would have the following table:

Table 1: Hypocritical behavior between two members of an organization - pure strategies and pay offs

\begin{tabular}{|c|c|c|c|}
\cline { 3 - 4 } \multicolumn{2}{c|}{} & \multicolumn{3}{c|}{ Actor2 } \\
\cline { 3 - 4 } \multicolumn{2}{c|}{} & Having a hypocritical behavior & Not having a hypocritical behavior \\
\hline & Not having a hypocritical behavior & V-c,$\quad v$ & v-c,$v-c$ \\
\cline { 2 - 4 } & Having a hypocritical behavior & 0,0 & $v, v-c$ \\
\hline
\end{tabular}

Where, the Nash equilibrium set is:

$N(\mathrm{G})=\{($ non - hypocritical behavior, hypocritical behavior $),($ non - hypocritical behavior,

hypocritical behavior $)\}$ 
It has to be noted that in a two-actor game, equilibrium is established when at least one of the two sides has a hypocritical behavior.

Now, the general game is designed for two members of the organization. The algebraic form of mixed strategies for two players can be as follows:

Table 2: Hypocritical behavior between two members of an organization - mixed strategies and pay offs

\begin{tabular}{|c|c|c|c|c|}
\hline \multirow{7}{*}{ Actor 1} & & & \multicolumn{2}{|l|}{ Actor 2} \\
\hline & & & $p$ & $1-p$ \\
\hline & & & $\mathrm{NH}$ & $H$ \\
\hline & \multirow{2}{*}{$q$} & \multirow{2}{*}{$\mathrm{NH}$} & $U_{1}(N H, N H)$ & $U_{1}(N H, H)$ \\
\hline & & & $U_{2}(N H, N H)$ & $U_{2}(N H, H)$ \\
\hline & \multirow{2}{*}{$1-q$} & \multirow[b]{2}{*}{$H$} & $U_{1}(H, N H)$ & $U_{1}(H, H)$ \\
\hline & & & $U_{2}(H, N H)$ & $U_{2}(H, H)$ \\
\hline
\end{tabular}

To model the general state of the game, we assume that actors play their strategies in a probabilistic manner. We also assume that the Actor 1 plays the Row 1 with the probability of $q$. Consequently, the actor will play the row 2 with the probability of 1-q, $Q=(q, 1-q)$. Similarly, the actor knows that the other actor will play with the combination $P=(p, 1-p)$. In this case, the expected value of the game, which is the pay-off expected by the Actor 1 , is calculated as follows:

$$
\begin{aligned}
& U_{1}(Q, P)=q p\left(u_{1}(N H, N H)\right)+q(1-p)\left(u_{1}(N H, H)\right) \\
&+(1-q) p\left(u_{1}(H, N H)\right)+(1-q)(1-p)\left(u_{1}(H, H)\right) \\
&= q\left(p u_{1}(N H, N H)+(1-p)\left(u_{1}(N H, H)\right)\right) \\
&+(1-q)\left(\frac{E_{1}(H, p)}{p\left(u_{1}(H, N H)+(1-p)\left(u_{1}(H, H)\right)\right)}\right) \\
&= q E_{1}(N H, p)+(1-q) E_{1}(H, p)
\end{aligned}
$$

The Actor 1 wishes to maximize its utility, so he would decide as follows:

$$
\begin{array}{ll}
p: E_{1}(\mathrm{NH}, \mathrm{p})>\mathrm{E}_{1}(\mathrm{H}, \mathrm{p}) & : \mathrm{q}=1 \\
p: E_{1}(\mathrm{NH}, \mathrm{p})<E_{1}(\mathrm{H}, \mathrm{p}) & : \mathrm{q}=0 \\
p: E_{1}(\mathrm{NH}, \mathrm{p})=E_{1}(\mathrm{H}, \mathrm{p}) & : \mathrm{q} \in\left[\begin{array}{ll}
0 & 1
\end{array}\right]
\end{array}
$$

\begin{tabular}{|c|c|c|c|}
\hline & & Remainin & -1 member \\
\hline & & All are hypocrites & At least one member is not hypocrite \\
\hline & $q \quad \mathrm{NH}$ & $\mathrm{V}-\mathrm{C}$ & $\mathrm{V}-\mathrm{C}$ \\
\hline \begin{tabular}{l|lllll} 
Actor 1 & 1 & & & \\
\end{tabular} & $1-q \quad \mathrm{H}$ & 0 & V \\
\hline
\end{tabular}

In the Table 2 , the Actor 1 plays his games based on the probability of the game played by the Actor $2(\mathrm{P})$. Inequalities (4) and (5) show that they only reflect two pure strategies from our mixed strategies set. Thus, the Equation (6) is the mixed Nash equilibrium of the game, in which, the pay-off for the Actor 1 remains constant for all values of q.

Now consider an organization. We assume that all employees, except the employee 1 or what we call the Actor 1 , play with the $P=(p, 1-p)$ strategy. Then, we calculate the best game function of the Actor 1 , and look for the Nash equilibrium of the game.

Table 3: Hypocritical behavior in an organization

According to Table 3, the expected value of the game, which is the pay-off expected by the Actor 1 , is calculated as follows:

$$
U_{1}(Q, P)=q(V-C)+(1-q)\left(0+V\left(1-(1-p)^{N-1}\right)\right)
$$




$$
\begin{aligned}
& p: V-C>V\left(1-(1-p)^{N-1}\right) \quad: q=1 \\
& p: V-C<V\left(1-(1-p)^{N-1}\right): q=0 \\
& p: V-C=V\left(1-(1-p)^{N-1}\right): q \in\left[\begin{array}{ll}
0 & 1
\end{array}\right]
\end{aligned}
$$

The Inequalities (7) and (8) show that these two are only two pure strategies from our mixed strategies set. The Inequality (9) is the Nash equilibrium combination of the game, where, no member of the organization wishes to change his game.

Equation (9) is derived by simplifying the equation (10):

$$
\frac{C}{V}=(1-p)^{N-1} \Rightarrow p=1-\left(\frac{C}{V}\right)^{\frac{1}{N-1}}
$$

If the Actor 1 equates its $q$ with the $p$, shown in the Equation (10), since this solution is a part of the best solution, the Actor 1 would have no motive to change his behavior.

Now we look more carefully into the Equation (10). The first thing that comes to the mind is that P (probability of non-hypocritical behavior), is inversely related to the number of members of the organization, or in other words, the probability of non-hypocritical behavior is inversely related to the organizational size.

According to the game introduced in the Table 3 , the probability that all the remaining $\mathrm{N}-1$ actors have hypocritical behaviors is (1-P) ${ }^{\mathrm{N}-1}$. In addition, the probability that at least one of the members has hypocritical behaviors will be 1-(1$P)^{N-1}$. Moreover, equation (10) shows that an increased $N$ reduces the value of $p$. On the other hand, a decreased value of $p$ increases the value of 1- $p$, and thereby, that of 1-(1-P) $)^{N-1}$. In other words, increasing the number of an organization's members increases the probability that all the remaining $n-1$ members have hypocritical behavior. behavior:

At this point, we are ready to calculate the probability that all members of the organization have hypocritical

$P($ All members bahave hypocritically $)=$

$P($ member $i$ bahaves hypocritically $) \times($ all remaining $N-1$ members bahave hypocritically $)$

$$
=(1-p) \times(1-p)^{N-1}
$$

Equation (10) shows that $(1-p)^{n-1}=C / V$ is a constant value. The whole equation (12) increases since the value of $(1-P)$ increases due to an increased $N$. This interesting result suggests that even though all assumptions are made to keep the people's willingness to non-hypocritical behavior high, an increase in the number of employees increases the probability that all members have hypocritical behaviors. In other words, the larger is the organizational size (number of members), the greater is the risk that all members of the organization turn to adopt a hypocritical behavior.

\section{Conclusion}

As discussed earlier, trust and the consequences of distrust in organizations are of significant importance. Since hypocritical behaviors are considered as a factor that destroys organizational trust, they have to be carefully examined and prevented. In this paper, the game theory was employed to model such behaviors in organizations, and investigate the effects of organizational size (in terms of the number of employees) in the dissemination of such behaviors in an organization. The modeling results revealed that an increase in the number of employees increases the probability of hypocritical behaviors. This finding is important from several aspects. First, our literature review suggests that although hypocritical behavior has not been addressed many in organizations, it can diminish trust in such settings. Thus, organizations are faced with a phenomenon that may have not been taken seriously; a phenomenon that spreads gradually. Results show that the dissemination of this phenomenon is associated with the number of employees. This suggests that prior to any form of development; organizations should address the hypocritical behavior within themselves; otherwise the level of hypocritical behavior will increase as the organizational size increases. For example, organizations can consider not having such behaviors as an organizational value and deal with and control them at the beginning of their occurrence to prevent them from growing in the organization.

\section{References}

Argyris, C. \& SCHON, D. A. 1974. Theory in practice: Increasing professional effectiveness, Jossey-Bass.

Aronson, E. 1999. Dissonance, hypocrisy, and the self-concept. Readings about the social animal, 219-236.

Aronson, E., Fried, C. \& Stone, J. 1991. Overcoming denial and increasing the intention to use condoms through the induction of hypocrisy. American Journal of Public Health, 81, 1636-1638. 
Barden, J., Rucker, D. D. \& Petty, R. E. 2005. "Saying one thing and doing another": Examining the impact of event order on hypocrisy judgments of others. Personality and Social Psychology Bulletin, 31, 1463-1474.

Batson, C. D., Kobrynowicz, D., Dinnerstein, J. L., Kampf, H. C. \& Wilson, A. D. 1997. In a very different voice: unmasking moral hypocrisy. Journal of personality and social psychology, 72,1335 .

Batson, C. D., Thompson, E. R. \& Chen, H. 2002. Moral hypocrisy: Addressing some alternatives. Journal of Personality and Social Psychology, 83, 330.

Batson, C. D., Thompson, E. R., Seuferling, G., Whitney, H. \& Strongman, J. A. 1999. Moral hypocrisy: appearing moral to oneself without being so. Journal of personality and social psychology, 77,525 .

Bigley, G. A. \& Pearce, J. L. 1998. Straining for shared meaning in organization science: Problems of trust and distrust. Academy of management review, 23, 405-421.

Braun, S., Peus, C., Weisweiler, S. \& FREY, D. 2013. Transformational leadership, job satisfaction, and team performance: A multilevel mediation model of trust. The Leadership Quarterly, 24, 270-283.

Brunsson, N. 1989. The organization of hypocrisy: talk, decisions and actions in organizations.

Brunsson, N. 1993. Ideas and actions: Justification and hypocrisy as alternatives to control. Accounting, Organizations and Society, 18, 489-506.

Buller, D. B. \& Burgoon, J. K. 1996. Interpersonal deception theory. Communication theory, 6, 203-242.

Cazier, J. A., Shao, B. B. \& LOUIS, R. D. S. 2007. Sharing information and building trust through value congruence. Information Systems Frontiers, 9, 515-529.

Cook, J. \& Wall, T. 1980. New work attitude measures of trust, organizational commitment and personal need non-fulfilment. Journal of occupational psychology, 53, 39-52.

Deal, T. E. \& Kennedy, A. A. 1982. Corporate cultures: The rites and rituals of organizational life. Reading/T. Deal, A. Kennedy.-Mass: Addison-Wesley, 98-103.

Dickerson, C. A., Thibodeau, R., Aronson, E. \& Miller, D. 1992. Using cognitive dissonance to encourage water conservation1. Journal of Applied Social Psychology, 22, 841-854.

Dirks, K. T. \& Ferrin, D. L. 2002. Trust in leadership: meta-analytic findings and implications for research and practice. Journal of applied psychology, $87,611$.

Fried, C. B. \& Aronson, E. 1995. Hypocrisy, misattribution, and dissonance reduction. Personality and Social Psychology Bulletin, 21, 925-933.

Gawthrop, L. C. 1997. Democracy, bureaucracy, and hypocrisy redux: A search for sympathy and compassion. Public Administration Review, 205-210.

Gibbons, R. 1992. Game theory for applied economists, Princeton University Press.

Gilby, T. 1979. Hypocrisy. Encyclopedic Dictionary of Religion. Washington, DC: Corpus Publications, 1752.

Golembiewski, R. T. \& Mcconkie, M. 1975. The centrality of interpersonal trust in group processes. Theories of group processes, 131, 185.

Griffin, D. W. \& Ross, L. 1991. Subjective construal, social inference, and human misunderstanding. Advances in experimental social psychology, 24, 319-359.

Holt, C. A. \& Roth, A. E. 2004. The Nash equilibrium: A perspective. Proceedings of the National Academy of Sciences, 101, 3999-4002.

Jansen, E. \& Von Glinow, M. A. 1985. Ethical ambivalence and organizational reward systems. Academy of Management Review, 10, 814-822.

Kramer, R. M. 1999. Trust and distrust in organizations: Emerging perspectives, enduring questions. Annual review of psychology, 50, 569-598.

Kramer, R. M. \& Lewicki, R. J. 2010. Repairing and enhancing trust: Approaches to reducing organizational trust deficits. The Academy of Management Annals, 4, 245-277.

Lammers, J., Stapel, D. A. \& Galinsky, A. D. 2010. Power increases hypocrisy moralizing in reasoning, immorality in behavior. Psychological Science, 21, 737-744.

LI, P. P., BAl, Y. \& XI, Y. 2012. The Contextual Antecedents of Organizational Trust: A Multidimensional Cross-level Analysis. Management and Organization Review, 8, 371-396.

Mayer, R. C., DAVIS, J. H. \& Schoorman, F. D. 1995. An integrative model of organizational trust. Academy of management review, 20, 709-734.

Mcallister, D. J. 1995. Affect-and cognition-based trust as foundations for interpersonal cooperation in organizations. Academy of management journal, 38, 24-59.

Mccornack, S. A. 1997. The generation of deceptive messages: Laying the groundwork for a viable theory of interpersonal deception.

Myerson, R. B. 1997. Game Theory: Analysis of Conflict, Harvard University.

Nash JR, J. F. 1950. The bargaining problem. Econometrica: Journal of the Econometric Society, 155-162.

Nyhan, R. C. 2000. Changing the Paradigm Trust and its Role in Public Sector Organizations. The American Review of Public Administration, 30, 87-109.

Osborne, M. J. \& Rubinstein, A. 1994. A course in game theory, MIT press.

Perez, L. F.-R. \& Robson, K. 1999. Ritual legitimation, de-coupling and the budgetary process: managing organizational hypocrisies in a multinational company. Management Accounting Research, 10, 383-407.

Philippe, T. W. \& Koehler, J. W. 2004. The effects of perceived organizational hypocrisy on intention to leave and job satisfaction. 
Review of Business Research, 3, 14-21.

Price, J. L. 1986. The Dictionary of Bible and Religion. Nashville: Abingdon.

Sankowska, A. 2013. Relationships between organizational trust, knowledge transfer, knowledge creation, and firm's innovativeness. The Learning Organization, 20, 85-100.

Shockley-Zalabak, P., Ellis, K. \& Winograd, G. 2000. Organizational trust: What it means, why it matters. Organization Development Journal, $18,35-48$.

Simoms, T. 2002. Behavioral integrity: The perceived alignment between managers' words and deeds as a research focus. Organization Science, 13, 18-35.

Stone, J., Aronson, E., Crain, A. L., Winslow, M. P. \& Fried, C. B. 1994. Inducing hypocrisy as a means of encouraging young adults to use condoms. Personality and Social Psychology Bulletin, 20, 116-128.

Stone, J. \& Fernandez, N. C. 2008. To practice what we preach: The use of hypocrisy and cognitive dissonance to motivate behavior change. Social and Personality Psychology Compass, 2, 1024-1051.

Tyler, T. R. 2003. Trust within organisations. Personnel review, 32, 556-568.

Velez, P. 2000. Interpersonal trust between a supervisor and subordinate. University of California, Berkeley. 